\title{
Chemical Durability, Specular Gloss, and Transmittance of Optical Glasses
}

\author{
By Donald Hubbard and Gerald F. Rynders
}

\begin{abstract}
The chemical durability of three types of optical glass (BSC 517, BaC 572, and F 620) and chemical Pyrex have been studied over an extended $\mathrm{pH}$ range by means of an interferometer procedure. The accompanying effect on the appearance (gloss retained) and on the transmittance of the specimens has also been determined. The results illustrate the confusion that might arise from choosing any of the above three properties as an indicator for the serviceability of optical glasses. Below $\mathrm{pH} 6$, in the range of maximum durability for the optical glasses, differential solution of the alkali and heavy metal oxides brings about the formation of silica-rich, reflection-reducing films, which decrease specular gloss of the surface and improve the transmittance of the specimens.
\end{abstract}

\section{Introduction}

As early as 1892 it was observed that old, tarnished photographic lenses sometimes gave more satisfactory performance than new lenses of the same aperture [1]. ${ }^{1} \quad$ Efforts to determine the reasons, for the purpose of improving the efficiency of optical systems, have resulted in the familiar modern lenses with reflection-reducing surfaces and increased transmittance [1 to 6]. Although the most effective nonreflecting surfaces are obtained by deposition of films of chosen index of refraction ${ }^{2}$ and controlled thickness, ${ }^{3}$ [5 to 8], less effective but useful films can be produced by leaching the silicate glasses with numerous aqueous solutions $[3,9,10]$. In the latter cases the rate of formation of these reflection-reducing films has been considered to be an indicator of the chemical durability of the glass $[10,11]$. As the three properties of glass, durability, nonreflecting films, and increased transmittance, seem to be so intimately associated, they have been compared in the present investigation over an extended $\mathrm{pH}$ range for three types of optical glasses and chemical Pyrex.

\footnotetext{
1 Figures in brackets indicate the literature references at the end of this paper.

${ }^{2} \mathrm{~A}$ film whose index of refraction is equal to the square root of the refrac tive index of the base glass.

${ }^{3}$ A layer whose thickness is approximately one-fourth the wavelength of light.
}

\section{Materials and Procedure}

The three optical glasses chosen for comparison with chemical Pyrex were a borosilicate crown (BSC 517), a barium crown (BaC 572), and a flint (F 620). ${ }^{4}$ The compositions of these glasses are given in table 1 .

TABLE 1. Composition (weight percent) of the glasses tested

\begin{tabular}{|c|c|c|c|c|}
\hline Oxide & BSC $517^{1}$ & $\mathrm{BaC} 572^{1}$ & F $620^{1}$ & $\begin{array}{c}\text { Chemical } \\
\text { Pyrex }{ }^{2}\end{array}$ \\
\hline $\mathrm{SiO}_{2}$ & 66.4 & 49.7 & 45.6 & 81.0 \\
\hline $\mathrm{B}_{2} \mathrm{O}_{3} \ldots$ & 12.4 & 3.6 & & 13.0 \\
\hline $\mathrm{Na}_{2} \mathrm{O}$ & 8.4 & 0.4 & 3.6 & 3.6 \\
\hline $\mathrm{K}_{2} \mathrm{O} \ldots$ & 11.8 & 7.7 & 5.2 & 0.2 \\
\hline $\mathrm{BaO}_{-}$ & & 30.8 & & \\
\hline $\mathrm{PbO}$ & & & 45.1 & \\
\hline $\mathrm{ZnO}$ & 0.5 & 7.2 & & \\
\hline $\mathrm{As}_{2} \mathrm{O}_{3--}$ & .5 & 0.2 & 0.5 & .002 \\
\hline $\mathrm{Sb}_{2} \mathrm{O}_{3 \ldots}$ & - & .4 & & \\
\hline $\mathrm{R}_{2} \mathrm{O}_{3-}$ & & & & 2. 2 \\
\hline
\end{tabular}

${ }^{1}$ Calculated from batch composition.

${ }^{2}$ Analysis by Francis W. Glaze.

The attack experiments were made by the interferometer method [12 to 15 ] because it offered a rapid and convenient means of studying the relative rates of solution of the glasses over a wide

\footnotetext{
4 Terminology recommended by the American Ceramic Society committee on glass nomenclature and standard definitions.
} 
$\mathrm{pH}$ range. Although the interferometer procedure is not highly accurate or precise, it is perhaps the only available method for measuring chemical durability that is equally fair to all types of glasses, regardless of their composition [16, 17]. Furthermore, as half of each specimen (Pulfrich slab) remains unexposed to the attacking solution, one is able to measure the desired three properties on a single specimen, namely, the chemical durability, the gloss retained, and the change in light transmittance. Of these three properties, the measurement of attack involves the greatest uncertainties; however, for the largest attacks encountered the interferometer procedure is considered to be sensitive to approximately one-quarter of a fringe.

Rectangular specimens (Pulfrich slabs 19 by 30 by $5 \mathrm{~mm}$, pitch polished on one face and optically flat to within one-half fringe) were partially immersed in the desired buffer solutions, the surfaces of which were covered with a thin layer of liquid petrolatum to prevent evaporation during the period of the test. Specimens of each glass were exposed for $6 \mathrm{hr}$ at $80^{\circ} \pm 0.2^{\circ} \mathrm{C}$ to Britton-Robinson universal buffer solutions [18] covering a $\mathrm{pH}$ range from 1.8 to 11.9 . This range was extended to $\mathrm{pH} 0.65$ by means of a sodium acetatehydrochloric acid buffer. All exposures were made simultaneously.

The extent of the attack was determined by observing the displacement of the interference fringes when the exposed specimens were placed under a fused-silica flat. Observations were made with a Pulfrich viewing apparatus by using unfiltered helium light for illumination.

The change in appearance of the glasses caused by the various treatments was evaluated by observing the percentage of specular gloss retained by the exposed area for $45^{\circ}$ incident beam compared with the unexposed portion of the specimen. The measurements were made by means of the Hunter Gloss Meter [19 to 21], by using an adapting shield for supporting the small specimens.

The transmittance of the treated and untreated areas was determined after the specimens had been reground on the unpolished surface with superfine emery to insure that this area was uniform and contributed no uncertainty to the measurements. Thus the change in transmittance resulting from attack is attributable to one surface. ${ }^{5}$ To obtain information concerning the effect on appearance of the surface brought about by increased attack in the alkaline range, the three optical glasses were exposed to 5 percent of $\mathrm{NaOH}$ solution at $80^{\circ} \mathrm{C}$ for different periods of time, ranging from $15 \mathrm{~min}$ to $4 \mathrm{hr}$.

\section{Data and Discussion}

The data plotted in figure 1 from table 2 show the curves for attack, gloss retained, and change in transmittance obtained for a borosilicate optical glass, BSC 517, after $6 \mathrm{hr}$ of exposure at $80^{\circ} \mathrm{C}$ over the range $\mathrm{pH} 0.65$ to $\mathrm{pH} 11.9$. This glass showed detectable attack in the acid range with an appreciable increase between $\mathrm{pH} 5$ and $\mathrm{pH}$ 9, followed by a more pronounced increase in attack for increasing alkalinity beyond $\mathrm{pH} 9$.

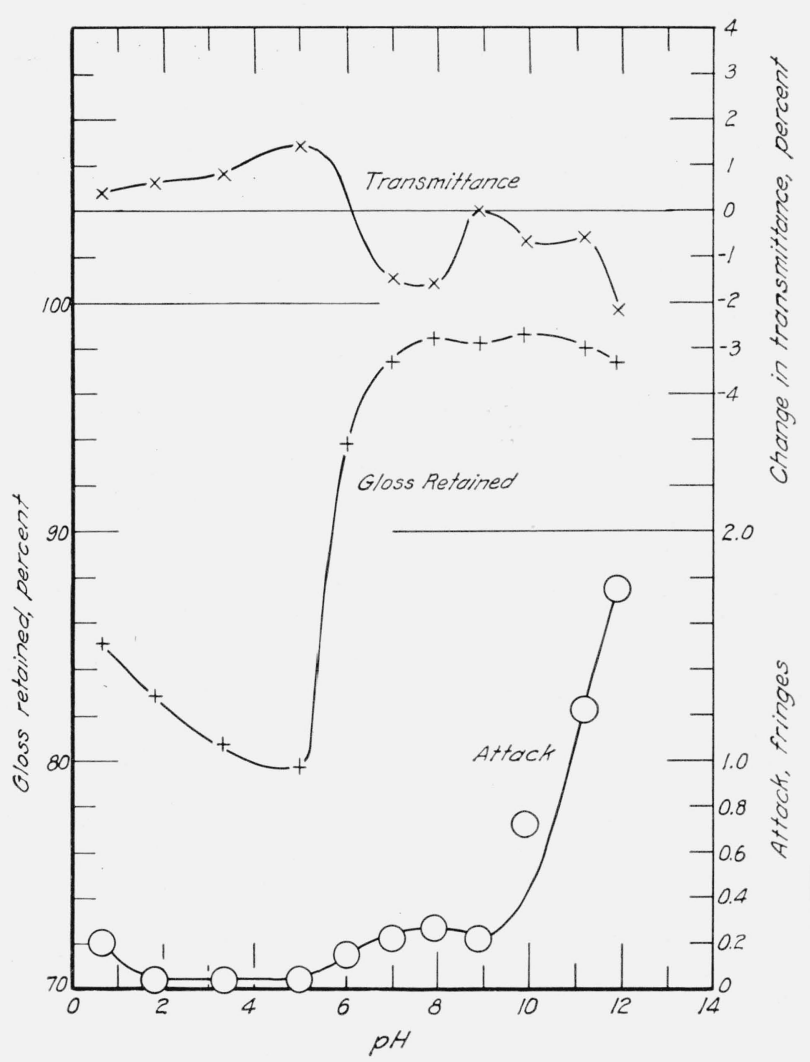

Figure 1. Comparison of the attack-pH curve with the accompanying effect on specular gloss of the surface and the change in iransmittance for BSC 517 optical glass after 6-hr exposure at $80^{\circ} \mathrm{C}$.

${ }_{5}^{5}$ Transmittance measurements were made by Richard S. Hunter, formerly of the Photometry and Colorimetry Section of the National Bureau of Standards. 
At no $\mathrm{pH}$ value does the chemical durability of this optical glass compare favorably with that for Pyrex, an acceptable laboratory glassware (fig. 2). It is interesting to note that Pyrex demonstrated little or no change in appearance (gloss retained) or transmittance for the entire $\mathrm{pH}$ range except for the high alkalinities above $\mathrm{pH} 11$, where the attack became increasingly vigorous. In contrast to the behavior of Pyrex, optical glass BSC 517 showed a large decrease in gloss in the $\mathrm{pH}$ region of optimum durability of the glass, with only a slight change in specular gloss for the region of more pronounced attack. However, the transmittance of the specimens showed an appreciable improvement in the $\mathrm{pH}$ range of maximum durability and a decrease in the $\mathrm{pH}$ range of increasing attack. Essentially these same features are shown in a somewhat exaggerated and confused fashion by the data obtained on the other optical glasses, $\mathrm{BaC} 572$ and $\mathrm{F} 620$ (figs. 3 and 4).

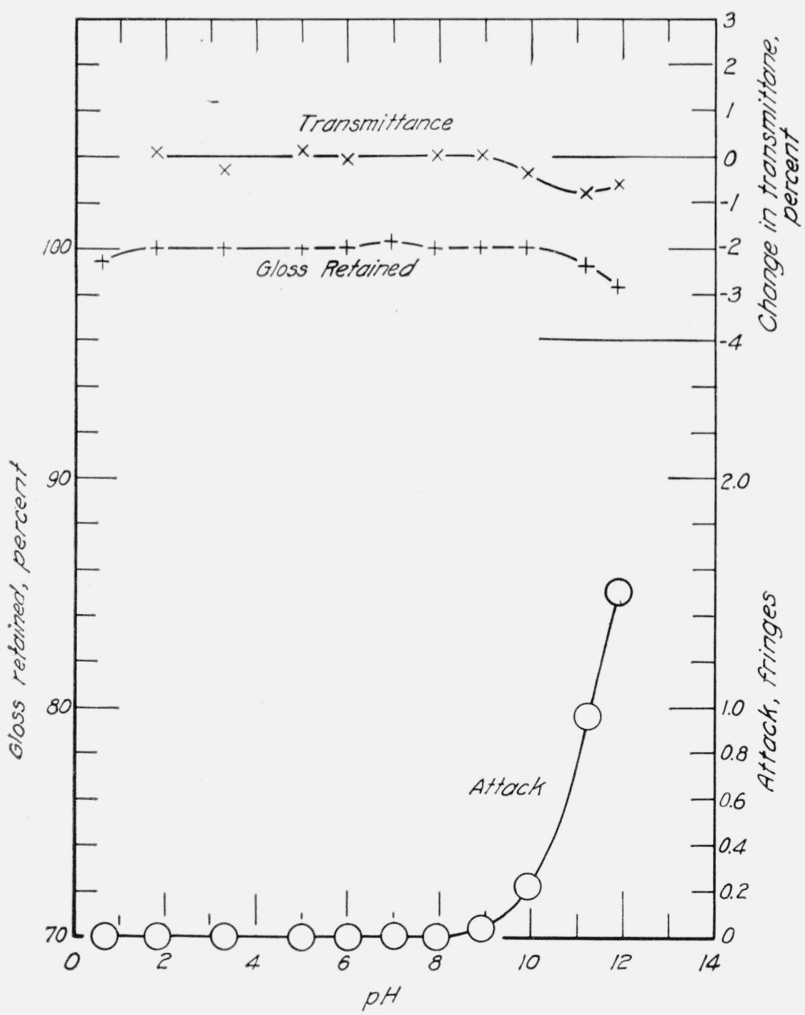

Figure 2. Comparison of the attack-pH curve with the accompanying effect on specular gloss of the surface and the change in transmittance for chemical Pyrex glass after 6-hr exposure at $80^{\circ} \mathrm{C}$.
TABLE 2. Values for chemical durability, gloss retained, and change in transmittance of three optical glasses and Pyrex after exposure for $6 \mathrm{hr}$ at $80^{\circ} \mathrm{C}$ to buffers in the range $\mathrm{pH}$ 0.65 to $\mathrm{pH} 11.9$

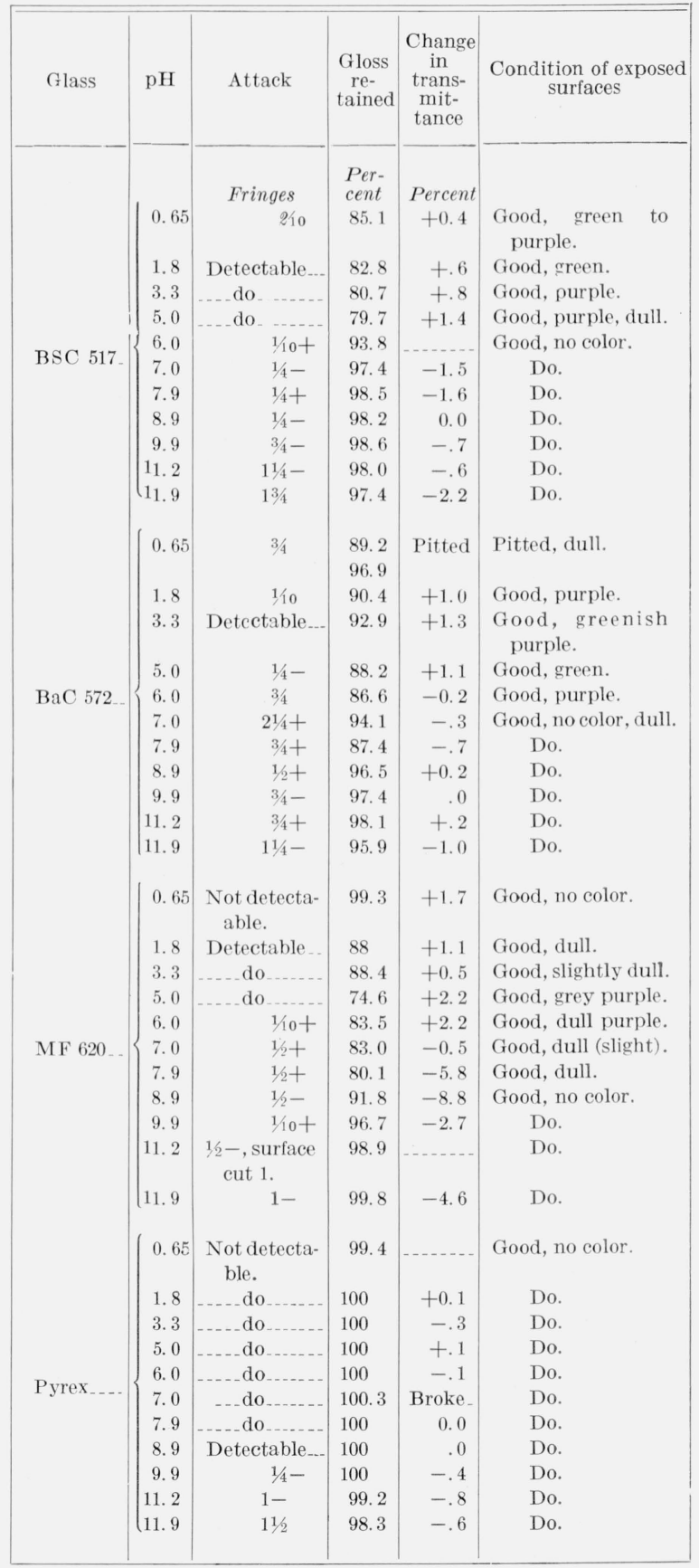

The gloss-pH curve for BSC 517 indicates that gloss might well be used under certain conditions as a sensitive indicator of the $\mathrm{pH}$ at which chemical changes take place between the glass and the buffer 


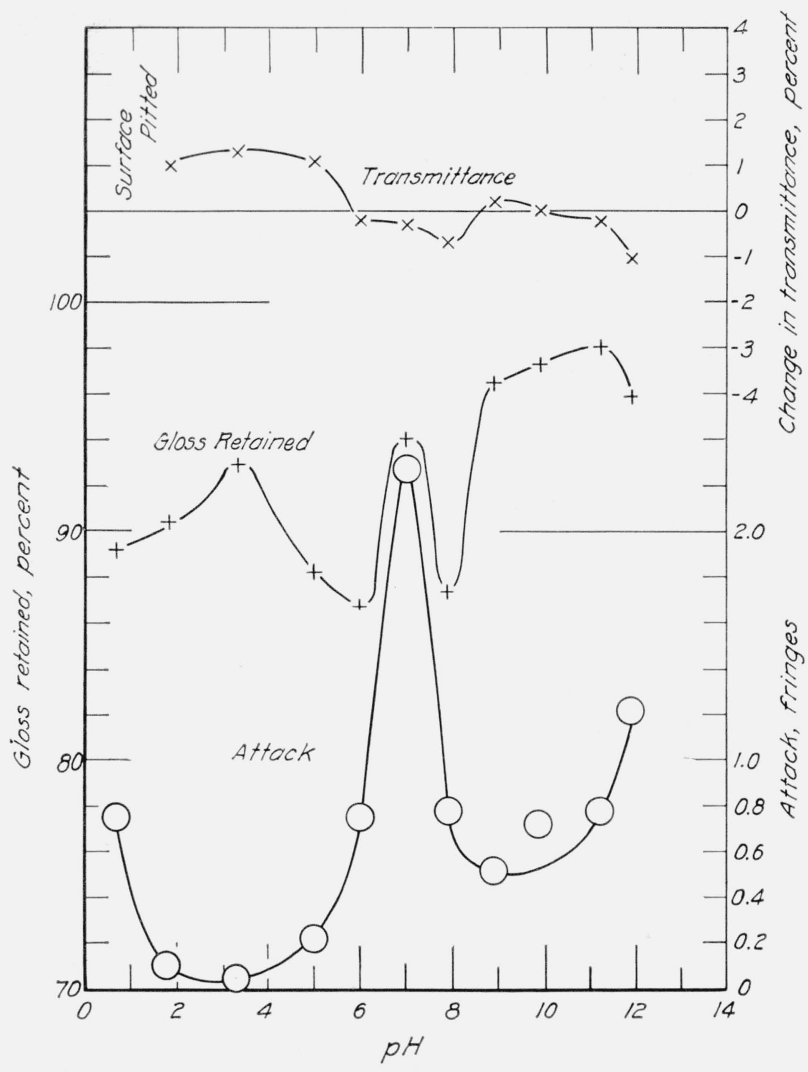

Figure 3. Compariscn of the attack-pH curve with the accompanying effect on specular gloss of the surface and the change in transmittance for $\mathrm{BaC} 572$ optical glass after 6-hr exposure at $80^{\circ} \mathrm{C}$.

solutions. For example, in figure 1, gloss is a more sensitive indicator of change in reaction near pH 5 than either the interferometric or transmittance curves. However, in the high-alkaline range beyond $\mathrm{pH} 9$ the gloss gives no indication of the vigorous attack upon the glass that is demonstrated by the interferometer.

This fact is further emphasized by the data for attack and gloss retained for specimens of the three optical glasses after exposure to 5-percent $\mathrm{NaOH}$ solution at $80^{\circ} \mathrm{C}$ for various periods of time (table 3 and fig. 5). The attack, although vigorous, did not seriously affect the appearance of the polished surfaces except in the case of the F 620 after 3- and 4-hr exposures. The attacktime curve for all of the glasses appears to be linear.

All of these results can be partially rationalized. In general, the durability of the three optical glasses is best in the acid range below $\mathrm{pH} 5$. In such solutions there is a preferential dissolving of
TABLE 3. Values for chemical durability and gloss retained for three typical optical glasses after exposure to 5-percent $\mathrm{NaOH}$ at $80^{\circ} \mathrm{C}$ for various periods of time

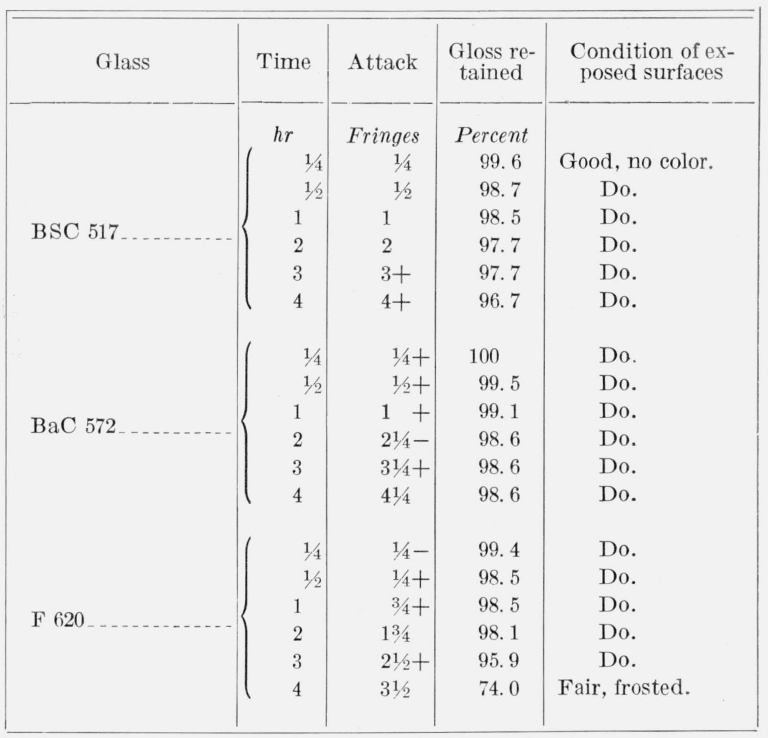

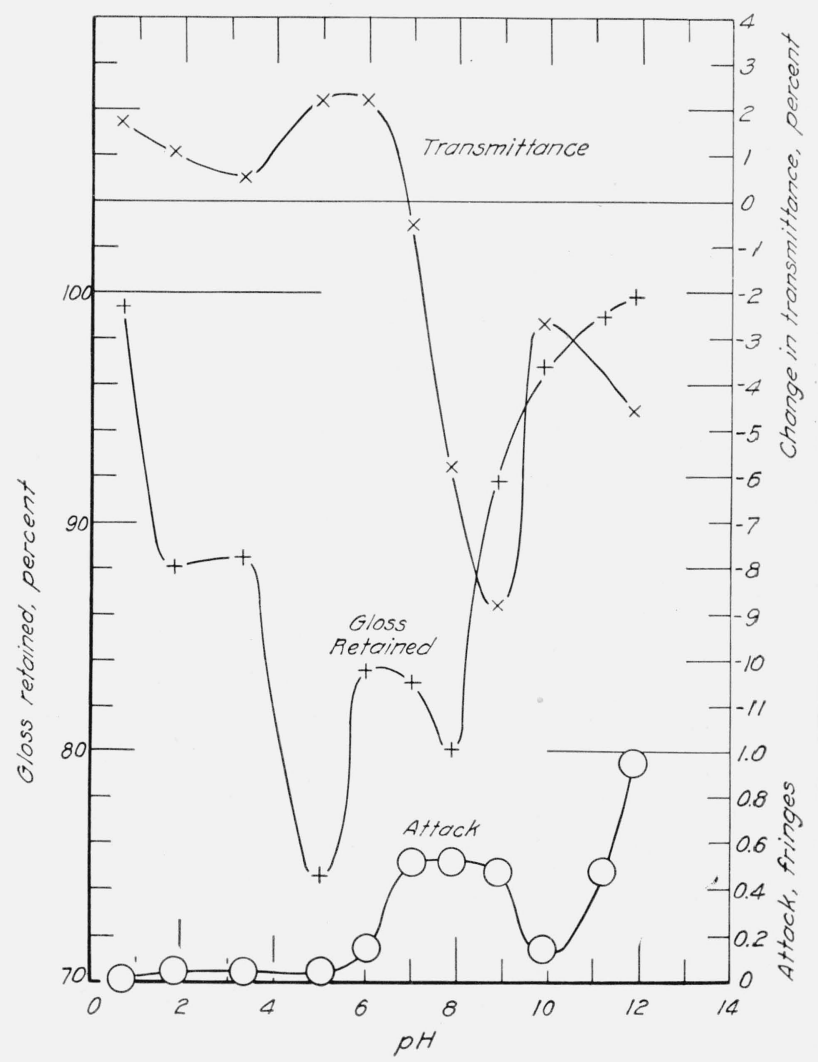

Figure 4. Comparison of the attack-pH curve with the accompanying effect on the specular gloss of the surface and the change in transmittance for F 620 optical glass after 6-hr exposure at $80^{\circ} \mathrm{C}$. 


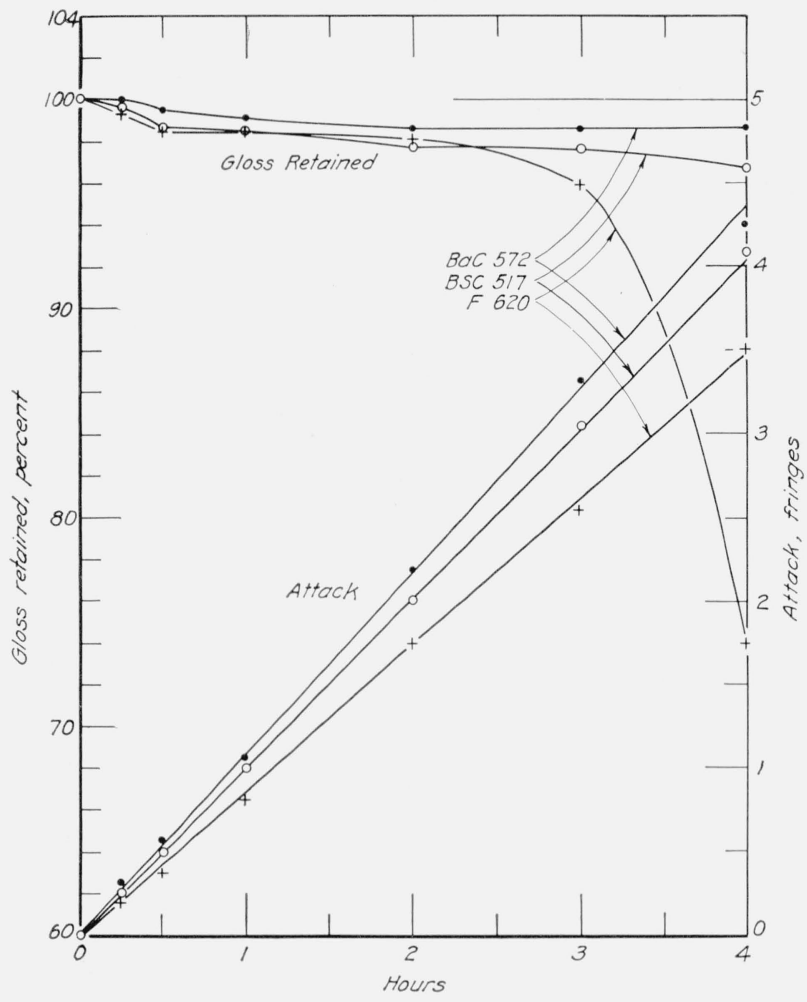

Figure 5.-Comparison of the attack-time curves and the accompanying change in specular gloss of the surfaces for three typical optical glasses exposed to 5 percent of $\mathrm{NaOH}$ at $80^{\circ} \mathrm{C}$.

alkali and other metal ions, leaving behind a silica-rich surface layer of index of refraction considerably lower than the index of the base glass. These silica-rich layers are of uncontrolled thickness and furnish reflection-reducing films that lower the specular gloss of the surface and improve the transmittance. However, these films are not of the correct index of refraction, $i_{\mathrm{film}}=$ $\sqrt{i_{\text {glass' }}}$, nor are they adjusted to the optimum thickness, $t_{\text {film }}=1 / 4 \quad \lambda$, for the maximum improvement of transmittance or reduction of surface reflection $[6,7,8]$. In the alkaline range the silica layer is dissolved, thus preventing the formation of a reflection-reducing film with the attendant improvement in transmittance. Within this range where silica-rich layers are no longer formed, interference colors do not appear (last column of table 2 ). Obviously, the amount of stain developed by an exposed sample of glass cannot be used as a reliable measure of the amount of attack [22]. However, useful and interesting information can be obtained from these stains if the specimens have been exposed to a solution in which certain constituents of the glass [23 to 26] are preferentially dissolved.

The attack on these optical glasses by the buffer solutions for the range $\mathrm{pH} 5$ to $\mathrm{pH} 8$ is accompanied by a reduction in transmittance. The more pronounced attack in the alkaline solutions above pH 9 does not seriously affect the percentage of transmittance of glasses BSC 517 and $\mathrm{BaC} 572$ until the highest $\mathrm{pH}$ is reached.

From this set of comparisons it is easy to understand how so much confusion might arise in choosing an adequate serviceability test for optical glasses. However, the data are interesting in that they show at a glance the best $\mathrm{pH}$ region for leaching to produce reflection-reducing surfaces and increased transmittance, with the accompanying improved performance of optical elements. The data on gloss retained and the general tarnished appearance of the surface after exposure in acid solutions could easily be used superficially and wrongly to condemn the optical glasses. It is evident that this test alone does not differentiate a desirable reflection-reducing film from a pitted, etched, or otherwise damaged surface. The transmittance data are necessary to establish this distinction.

\section{Conclusions}

The specimens used in the interferometer procedure for determining the chemical durability of glass lend themselves readily to a quantitative evaluation of the change in appearance (gloss retained) and the transmittance of the glass brought about by controlled exposures to solutions. The results obtained present an over-all picture of some desirable as well as undesirable characteristics of the optical glasses studied. The data reemphasized the difficulty of using any one of the three properties, chemical durability, gloss retained, or change in transmittance after exposure, alone as an indicator of serviceability. In fact, in the absence of additional information, such as long-time atmospheric-exposure test or hygroscopicity of the glass, it is doubtful that these three properties either singly or combined are a reliable indicator of the ability of optical glasses to maintain clear polished surfaces in service. 


\section{References}

[1] H. D. Taylor, The adjustment and testing of telescope objectives (T. Cook, York, Eng., 1896).

[2] F. Kollmorgen, Trans. Illum. Eng. Soc. 11, 220 (1916).

[3] F. E. Wright, The manufacture of optical glass and of optical systems. U. S. Ordnance Dept. Document 2037, (Govt. Printing Office, Washington 25, D. C., 1921).

[4] J. Strong, J. Opt. Soc. Am. 26, 73 (1936).

[5] C. H. Cartwright and A. F. Turner, Bul. Am. Phys. Soc. 13, 10 (1938).

[6] K. B. Blodgett, Phys. Rev. 55, 391 (1939).

[7] C. H. Cartwright, J. Opt. Soc. Am. 30, 110 (1940).

[8] C. H. Cartwright and A. F. Turner, Decreasing the reflection of light from surfaces such as glass lenses. U. S. Patent 2,207,656.

[9] Frank L. Jones and Howard J. Homer, J. Opt. Soc. Am. 31, 34 (1941).

[10] Frank L. Jones, J. Soc. Motion Picture Engrs. 37, 256 (1941).

[11] Donald Hubbard and Edgar H. Hamilton, J. Research NBS 27, 143 (1941) RP1409.

[12] Relative durability of optical glass, Tech. News Bul. NBS 221, p. 88 (1935).

[13] E. Berger, Glastech. Ber. 14, 351 (1936).

[14] Donald Hubbard, Edgar H. Hamilton, and Alfred N Finn, J. Research NBS 22, 339 (1939) RP1187.
[15] Donald Hubbard and Gerald F. Rynders, J. Research NBS 39, 561 (1947) RP1848.

[16] G. W. Morey, The properties of glass (Reinhold Publishing Corp., New York, N. Y., 1938).

[17] C. J. Phillips, Glass: The miracle maker (Pitman Publishing Corp., New York, N. Y., 1941).

[18] H. T. S. Britton, Hydrogen ions, $2^{\text {d }}$ ed., table 57(c) p. 225 (D. Van Nostrand \& Co., Inc., New York, N. Y., 1932).

[19] Richard S. Hunter, Natl. Paint, Varnish Lacquer Assn. Circ. 456, p. 69 (1934).

[20] Richard S. Hunter, Proc. Am. Soc. Testing Materials 36, [2] 783 (1936).

[21] Richard S. Hunter, J. Research NBS 18, 19 (1937) RP958

[22] M. S. Tarnopol and A. E. Junge, Am. Ceram. Soc. 29, 36 (1946).

[23] E. Berger, J. Soc. Glass Tech. 20, 257 (1936).

[24] Frank L. Jones, J. Am. Ceram. Soc. 24, 119 (1941).

[25] Gordon F. Brewster, Norbert J. Kreidl, and Tayler G. Pott, J. Soc. Glass Tech. 31, 153 (1947).

[26] Frank L. Jones and T. J. Zak, U. S. Patent 2,369,741 (1945).

Washington, May 5, 1948. 